\title{
The Relationship between Low Ocular Perfusion Pressure with Acute Non-Arterial Anterior Ischemic Optic Neuropathy
}

\section{Xiaotang Wang}

Honghui Hospital https://orcid.org/0000-0002-7706-1069

Runsheng Wang ( $\square$ wangrunsheng0602@126.com )

https://orcid.org/0000-0002-7868-5519

\section{Ying Wang}

Honghui Hospital

\section{Xu Wang}

Honghui Hospital

Research article

Keywords: Ocular perfusion pressure, ANAION, Correlation

Posted Date: June 4th, 2020

DOl: https://doi.org/10.21203/rs.3.rs-31612/v1

License: (c) (i) This work is licensed under a Creative Commons Attribution 4.0 International License.

Read Full License 


\section{Abstract}

Objective: To investigate the relationship between low ocular perfusion pressure (OPP) with acute nonarterial anterior ischemic optic neuropathy (ANAION).

Methods: Forty- six patients (46 eyes) with ANAION from July 2010 to December 2016 were retrospectively analyzed. The 24-h intraocualr pressure (IOP) in sitting position was measured by noncontact tonometer. The brachial artery systolic blood pressure (SBP) and diastolic blood pressure (DBP) were simultaneously measured by electrocardiogram monitor. The 24-h OPP was calculated according to the measured blood pressure and intraocular pressure: OPP $=45 \%$ DBP-IOP. OPP $<10 \mathrm{mmHg}$ was defined as low OPP. Sudden visual acuity declining or visual field defect was recorded as the attack of ANAION. 24h was divided into four periods: period A (1-6 A.M), period B (6-12 A.M), period C (12-18 P.M) and period D (18-24 P.M). The correlation between low OPP and ANAION was analyzed. Statistical method was used by Person correlation analysis.

Results: There was a statistical difference in the low OPP in the four periods $(P<0.05)$. The most common period of low OPP was period A (1-6 A.M), with the incidence of low OPP as high as $58.3 \%$. There was a statistical difference in the incidence of ANAION in the four periods $(P<0.05)$. Most common time period of ANAION was also period A (1-6 A.M), with the incidence rate as high as $46.3 \%$. Person correlation analysis showed that the period of low OPP was associated with the period of ANAION onset $(r=0.934, P$ $<0.05)$.

Conclusion: There was a significant clinical correlation between low OPP and ANAION. Period A (1-6 A.M) was the high-risk period for low OPP and ANAION. The occurrence of ANAION can be reduced by elevating the OPP to improve the blood perfusion of the anterior optic nerve.

\section{Introduction}

Acute non-arteritic anterior ischemic optic neuropathy (ANAION) is the most common acute optic nerve disease in patients over 50 years old. The onset time of ANAION is often in the morning, with the clinical manifestations includng sharp declining of visual acuity, edema of optic nerve head, and quadrant or upper and lower (mostly horizontal) visual field defects associated with physiological blind spots [1, 2, 3]. Currently, the pathogenesis of ANAION is still not clear. Insufficient blood supply of the short posterior ciliary artery (SPCA) may be the main cause of ANAION. Acute non-perfusion or hypoperfusion is the hemodynamic basis for ANAION [4, 5]. However, the clinical correlation between OPP and ANAION is still controversial. Therefore, we retrospectively analyzed the 24-h OPP of 46 patients with ANAION to investigate the clinical correlation between low OPP and the attack of ANAION.

\section{Patients And Methods}

\section{Patients}


Forty-six patients with ANAION admitted to our hospital from July 2010 to December 2016 were collected. ANAION was diagnosed by analysing the peri-disc nerve fiber thickness, visual field, visual electrophysiology, and fundus fluorescein angiography: 1) sudden vision acuity loss or visual field damage, no eye pain, 2) relative afferent pupillary reflex disorder $(+), 3)$ paleness and unclear boundary in the localized or the overall optic disc, 4) thickening of nerve fiber layer around optic disc, 5) quadrantal visual field defect associated with physiological blind spot, 6) low fluorescence in localized optic disc before and during the early arterial period. Inclusion criteria included diagnosed ANAION, detailed onset time of ANAION, and blood pressure and intraocular pressure monitored for 24 hours.

Exclusion criteria were included as follow. First, patients with POAG, optic neuritis, optic disc vasculitis, Leber hereditary optic neuropathy and drug-induced optic neuropathy were excluded. Second, patients with intracranial and intraorbital lesions causing vision acuity loss or visual field damage by CT and MRI scanning were excluded. Third, patients with macular lesions, high myopia, refractive interstitial opacity, optic disc burial vitreous membrane warts, and hypertension were excluded.

Blood pressure, intraocular pressure (IOP) and OPP

24-h IOP in the sitting position were measured by non-contact tonometer (nidek-2000, Japan). IOP was measured for 3 consecutive times and the average value of IOP was calculated. Goldmann tonometer was used to correct the results of two tonometers. The values measured by the two tonometers were normal. At the same time, the brachial systolic blood pressure (SBP) and diastolic blood pressure (DBP) in the sitting position were measured by electrocardiogram monitor (Mindry-AQ, shenzhen). Blood pressure and IOP were measured hourly for 24 hours.

The patient was placed in a relatively fixed ward during blood pressure and IOP measuring. Before measuring, we routinely conducted propaganda and education to the patients and obtained their cooperation. In the daytime, stay in bed during the day or engage in daily activities in the ward, avoiding activities that increase blood pressure or heart rate (e.g. climbing stairs). Stay in bed from 9 p.m. to 7 a.m. in the next day. Alcohol, strong tea, coffee and other high-calorie diet were not recommended. Drugs affecting IOP and blood pressure were banned in 3 days before measurement. The measurements were made by the same trained nurse with standard operation. The accuracy of tonometer and electrocardiogram monitor were regularly corrected.

Blood pressure and IOP of ANAION patients were recorded for $24 \mathrm{~h}$. According to IOP and blood pressure, OPP was calculated: OPP $=45 \%$ DBP- IOP [6, 7] (Table 1). $10 \mathrm{mmHg}$ of Hayreh was the OPP risk value of anterior optic ischemia [8]. The OPP value $\leq 10 \mathrm{mmHg}$ is determined as low OPP. Patients with low OPP at $\geq 2$ points were confirmed as having low OPP. The onset time of ANAION patients was the time of visual acuity loss and/or visual field defect. 
Table 1

24-h blood pressure, IOP and OPP ( $\mathrm{mmHg}$ ).

\begin{tabular}{|c|c|c|c|c|}
\hline Time & SBP & DBP & IOP-R & IOP-L \\
\hline 9:00 & 135 & 89 & 19.0 & 18.0 \\
\hline 10:00 & 130 & 81 & 18.0 & 16.0 \\
\hline 11:00 & 140 & 87 & 17.0 & 18.5 \\
\hline $12: 00$ & 131 & 77 & 17.0 & 15.0 \\
\hline 13:00 & 129 & 79 & 18.5 & 17.0 \\
\hline $14: 00$ & 134 & 82 & 17.5 & 18.0 \\
\hline 15:00 & 127 & 78 & 18.0 & 17.0 \\
\hline $16: 00$ & 124 & 72 & 15.0 & 17.0 \\
\hline 17:00 & 126 & 83 & 18.7 & 18.5 \\
\hline 18:00 & 132 & 81 & 19.0 & 18.5 \\
\hline 19:00 & 137 & 84 & 18.0 & 20.5 \\
\hline 20:00 & 130 & 70 & 19.0 & 18.5 \\
\hline 21:00 & 135 & 89 & 20.0 & 19.5 \\
\hline $22: 00$ & 140 & 87 & 19.0 & 19.0 \\
\hline 23:00 & 131 & 70 & 20.5 & 17.5 \\
\hline $24: 00$ & 129 & 68 & 19.0 & 18.0 \\
\hline 1:00 & 124 & 65 & 20.0 & 20.0 \\
\hline 2:00 & 127 & 61 & 20.5 & 21.5 \\
\hline 3:00 & 125 & 63 & 22.0 & 20.5 \\
\hline 4:00 & 128 & 64 & 22.5 & 21.0 \\
\hline 5:00 & 131 & 62 & 23.0 & 20.7 \\
\hline 6:00 & 132 & 70 & 21.0 & 18.0 \\
\hline 7:00 & 139 & 73 & 20.0 & 19.5 \\
\hline 8:00 & 141 & 74 & 21.0 & 19.0 \\
\hline
\end{tabular}




\section{Low Opp And Onset Time In Anaion Patients}

Based on analyzing $24 \mathrm{~h}$ blood pressure, IOP and OPP of 46 patients with ANAION, it was found that $24 \mathrm{~h}$ or $12 \mathrm{~h}$ OPP were not lower than $10 \mathrm{mmHg}$, but OPP was lower than $10 \mathrm{mmHg}$ only at several time periods. The time when low OPP occurred was defined as the time point of low OPP. If there were 8 time periods of OPP less than $10 \mathrm{mmHg}$ during $24 \mathrm{~h}$, the time points of low OPP was 8 . The occurrence times of low OPP were 20:00, 22:00, 1:00, 3:00, 4:00, 5:00, 6:00 and 7:00, respectively (Table 2). At the same time, the time of visual acuity loss and/or visual field defect was determined as the onset time of ANAION patients. For the convenience of observation and statistical analysis, the 24 hours were divided into four periods: period A (1-6 A.M), period B (6-12 A.M), period C (12-18 P.M) and period D (18-24 P.M) (Table 3). 
Table 2

24-h OPP (mmHg)and onset of ANAION.

\begin{tabular}{|c|c|c|c|c|}
\hline Time & OPP-R & OPP-L & Low OPP & Onset of ANAION \\
\hline 9:00 & 21.45 & 20.45 & & \\
\hline 10:00 & 22.1 & 27.1 & & \\
\hline 11:00 & 19.9 & 18.9 & & \\
\hline $12: 00$ & 19.2 & 15.2 & & \\
\hline 13:00 & 15.65 & 11.65 & & \\
\hline $14: 00$ & 18.1 & 19.1 & & \\
\hline $15: 00$ & 14.85 & 15.85 & & \\
\hline $16: 00$ & 13.45 & 12.95 & & \\
\hline 17:00 & 11.25 & 10.25 & & \\
\hline 18:00 & 13.15 & 11.15 & & \\
\hline 19:00 & 13.95 & 14.95 & & \\
\hline 20:00 & 13.25 & 8.25 & ( & \\
\hline 21:00 & 17.2 & 13.2 & & \\
\hline 22:00 & 11.15 & 9.15 & ( & \\
\hline 23:00 & 15.2 & 14.2 & & \\
\hline 24:00 & 16.2 & 15.2 & & \\
\hline 1:00 & 10.15 & 9.65 & 口 & \\
\hline 2:00 & 11.35 & 10.05 & & \\
\hline 3:00 & 13.05 & 9.05 & ( & ૫ \\
\hline $4: 00$ & 7.9 & 4.9 & ? & \\
\hline $5: 00$ & 5.5 & 2.0 & ( & \\
\hline $6: 00$ & 11.60 & 9.6 & ૫ & \\
\hline 7:00 & 11.05 & 9.05 & ૫ & \\
\hline 8:00 & 16.1 & 13.1 & & \\
\hline
\end{tabular}

The time points of low OPP was 8 , and onset of ANAION was 7Am. OPP- ocular perfusion pressure, Rright, L-left. 
Table 3

Incidence of low OPP and onset of ANAION in different time point.

\begin{tabular}{|c|c|c|}
\hline Time & Low OPP (N) & ANAION (N) \\
\hline $1: 00$ & 0 & 0 \\
\hline $2: 00$ & 2 & 0 \\
\hline 3:00 & 3 & 1 \\
\hline 4:00 & 4 & 2 \\
\hline $5: 00$ & 6 & 7 \\
\hline $6: 00$ & 2 & 11 \\
\hline 7:00 & 2 & 2 \\
\hline 8:00 & 1 & 0 \\
\hline 9:00 & 0 & 1 \\
\hline $10: 00$ & 1 & 0 \\
\hline $11: 00$ & 0 & 0 \\
\hline $12: 00$ & 0 & 0 \\
\hline $13: 00$ & 0 & 1 \\
\hline $14: 00$ & 2 & 2 \\
\hline $15: 00$ & 2 & 4 \\
\hline $16: 00$ & 0 & 1 \\
\hline $17: 00$ & 1 & 1 \\
\hline $18: 00$ & 0 & 1 \\
\hline $19: 00$ & 0 & 1 \\
\hline $20: 00$ & 1 & 1 \\
\hline $21: 00$ & 2 & 2 \\
\hline $22: 00$ & 0 & 1 \\
\hline 23:00 & 0 & 0 \\
\hline $24: 00$ & 0 & 0 \\
\hline Total & 29 & $39^{\square}$ \\
\hline
\end{tabular}


Table 4

Low OPP and onset of ANAION in different time period.

\begin{tabular}{|lll|}
\hline Time period & Low OPP(n) & Onset of ANAION(n) \\
\hline $\mathrm{A}(1 \sim 6 \mathrm{Am})$ & 17 & 21 \\
$\mathrm{~B}(6 \sim 12 \mathrm{Am})$ & 4 & 3 \\
\hline $\mathrm{C}(12 \sim 18 \mathrm{Pm})$ & 5 & 10 \\
\hline $\mathrm{D}(18 \sim 24 \mathrm{Pm})$ & 3 & 5 \\
\hline
\end{tabular}

Table 5

Correlation analysis of Low OPP and onset of ANAION.

\begin{tabular}{|lll|}
\hline Time period & Low OPP(n,\%) & Onset of ANAION(n,\%) \\
\hline$A(1 \sim 6 A m)$ & $17(58.3)$ & $21(46.3)$ \\
\hline$B(6 \sim 12 A m)$ & $4(14.5)$ & $3(6.8)$ \\
\hline$C(12 \sim 18 P m)$ & $5(16.5)$ & $10(21.2)$ \\
\hline$D(18 \sim 24 P m)$ & $3(10.7)$ & $5(9.7)$ \\
\hline 2 & 65.921 & 32.006 \\
$P$ & $\leq 0.0001$ & $\leq 0.0001$ \\
\hline$r$ & 0.934 & \\
\hline$P$ & 0.046 & \\
\hline
\end{tabular}

\section{Statistical analysis}

The Person correlation was used to analyze the correlation between low OPP and ANAION. SPSS22.0 was used for statistical analysis, and $\mathrm{P}<0.05$ was statistically significant.

\section{Results}

The 46 patients with ANAION included 26 males ( 26 eyes) and 20 females (20 eyes). The age ranged from 38 to 73 years old, with an average age of $(60.5 \pm 2.3)$ years old. There were 8 cases with diabetes mellitus, 11 cases with myocardial ischemia, and 11 cases with cerebral infarction. The onset time of ANAION ranged from one week to 3week. In 29 cases (63\%, 29/46), OPP was low and the hypoperfusion point was at least 2. The occurrence of low OPP was higher in period A (17 cases, $58.3 \%$ ), followed by period C (5 cases, $16.5 \%)$. Twenty-one (46.3\%) cases had ANAION attack in the morning and six (14\%) cases after siesta.

The number of cases with ANAION and low OPP over time. 
Low OPP and onset of ANAION mostly occurred in the period from sleep at night to early morning.

\section{Onset of ANAION was associated with low OPP in the time period.}

There was a statistical difference in the incidence of low OPP in the four time periods $(P<0.05)$. The most common period of low OPP was period A (1-6 A.M), with the incidence of low OPP as high as $58.3 \%$. There was a statistical difference in the incidence of ANAION in the four periods $(P<0.05)$. Most common time period of ANAION was also period A (1-6 A.M), with the incidence rate as high as $46.3 \%$. Person correlation analysis showed that the period of low OPP was associated with the period of ANAION onset $(r=0.934, P<0.05)$. The Person correlation analysis found that the low OPP period was correlated with the onset period of ANAION $(r=0.934, P=0.046)$.

\section{Discussion}

Low OPP is an important risk factor for ANAION. OPP is driving force of blood supply to the anterior optic nerve. Hayreh found that vessels in the papilla of optic nerve and choroidal membrane were not filled with blood when OPP was less than $10 \mathrm{mmHg}$ by fundus fluorescein angiography [8]. Studies showed that ANAION was caused by multiple local and systemic risk factors such as small optic disc and superficial optic cup, insufficient blood supply of anterior optic nerve, and vascular self-regulation disorder. Most of all, low OPP plays a major or important role in its pathogenesis $[5,10,11]$. Although there is a lack of large scale prospective studies on the correlation between OPP and ANAION, low OPP is one of the risk factors for ANAION, which has been accepted by most scholars. In our study, there was a significant correlation between low OPP and onset of ANAION in the time period $(r=0.934, P<0.05)$, which was consistent with relevant previous studies.

\section{Period A (1-6 am) is the high-risk period for the incidence of low OPP and ANAION.}

In 1994, Hayrech proposed that the incidence of ANAION was related to the low diastolic blood pressure at night and the sharp decrease in anterior optic nerve perfusion caused by poor blood circulation in the posterior ciliary artery [12]. Wang runsheng studied the blood pressure in 50 patients with ANAION and 50 healthy subjects and found that DBP in ANAION at night was lower than the control group [13]. Our study found that DBP in patients with ANAION significantly decreased compared with the control group $(\mathrm{P}<$ 0.05), particularly in the whole period A. DBP could be reduced to $60 \mathrm{mmHg}$ or lower. This was consistent with the research results by Hayrech and wang runsheng. IOP at night was significantly higher than during the daytime, and reached its highest level from deep sleep to wakefulness [14, 15]. IOP increased significantly when the position changed from sitting to supine position or lateral position $[16,17,18]$. IOP in the lateral position was higher than supine position $[16,17,18]$. Postural changing that caused IOP may be also an important risk factor for the onset of ANAION [19]. Therefore, low DBP at night, high IOP and the low OPP are the main reasons for the occurrence of ANAION in the period from falling asleep at night to getting up in the morning. OPP physiological circadian rhythm loss caused by ascular autonomic nerve regulation disordermay be also a part of the pathogenesis of ANAION $[20,21,22,23]$. 
Closely monitoring blood pressure and IOP in high-risk period for reducing the incidence of low OPP.

When OPP excessively reduces, the time of DBP of the short posterior ciliary artery at the critical level exceeds its own compensation limit and tolerance. If the patients themselves have anatomic bases such as small optic disc and shallow optic cup, the small vessels in the narrow environment in front of the optic disc sieve plate are limited and not easy to self-regulate. At this time, ANAION is more likely to occur after prolonged hypoperfusion, which leads to optic nerve ischemia behind the optic nerve papilla and sieve plate. Therefore, for patients with small optic disc and superficial optic cup, night blood pressure, IOP and OPP should be closely monitored. If necessary, the OPP should be improved to increase the blood flow of anterior optic nerve $[24,25]$ and reduce the occurrence of ANAION (especially iatrogenic ANAION). The efficacy of this method could be evaluated by FFA, visual field, vision acuity and OCT.

\section{Conclusion}

Low OPP was significantly associated with the incidence of ANAION. Period A (1 Am 6Am) is the highrisk period for the occurrence of low OPP and ANAION.

\section{Abbreviations}

ANAION: Acute Non-arterial Anterior Ischemic Optic Neuropathy; OPP: Ocular Perfusion Pressure; IOP: Intraocualr Pressure; SBP: Systolic Blood Pressure; DBP: Diastolic Blood Pressure.

\section{Declarations}

\section{Acknowledgements}

We acknowledge the patients and their proxies.

\section{Funding}

No funding was received regarding the manuscript by any of the authors.

\section{Availability of data and materials}

None.

\section{Authors' contributions}

Conception and design: RSW; acquisition of data: XTW; statistical analysis and interpretation of data: XTW, YW; drafting the article: RSW; critically revising the article: XW, RSW; reviewed submitted version of manuscript: all authors; approved the final version of the manuscript on behalf of all authors: RSW. All authors made substantial contribution to this manuscript meeting authorship criteria, agreed to be accountable for all aspects of the work. 


\section{Ethics approval and consent to participate}

This study was reviewed and approved by our Institutional Ethics Committee on Human Research.

\section{Competing interests}

The authors declare that there are no competing interests.

\section{References}

1. Hayreh SS, Podhajsky PA, Zimmerman B. Nonarteritic anterior ischemic optic neuropathy: time of onset of visual loss. Am J Ophthalmol. 1997;124:641-7.

2. Wang RS. Lv PL. Observation of the efficacy of several treatment strategies on patients with nonarteritic anterior ischemic optic neuropathy at edema stage. Chin $\mathrm{J}$ clinicians (electronic edition). 2011;5(12):3469-70.

3. Hayreh SS. Blood flow in the optic nerve head and factors that may influence it. Prog Retin Eye Res. 2001;20:595-624.

4. Wang Q. Jiang LB.The current pathogeny and diagnosis of nonarteritic anterior ischemic optic neuropathy. Chinese J Ophthalmologic Medicine (Electronic Edition). 2013;3(1):5-9.

5. Li FM. Ophthalmic arterial pressure measurement. Chinese ophthalmology, people's medical publishing house, 2nd Ed: 677.

6. Vital P, Costa A, Harris D, Anderson, et al. Ocular perfusion pressure in glaucoma. Acta Ophthalmol. 2014;92:e252-66.

7. Hayreh SS. Inter-individual variation in blood supply of the optic nerve head. Doc Ophthalmol. 1985;59:217-46.

8. Wang RS, Tong JA, Wang X. Relationship between blood pressure, intraocular pressure and anterior ischemic optic neuropathy. J practical ophthalmology. 1993;2:407-9.

9. Yang JM. Sang Woo Park, et a1.Postural effects on intraocular pressure and ocular perfusion in patients with non-arteritic anterior ischaemic optic neuropathy. BMC Ophthalmology. 2017;17(47):2.

10. Hayreh SS, Zimmerman MB. Nonarteritic anterior ischemic optic neuropathy: natural history of visual outcome. Ophthalmology. 2008;115:298-305.

11. Wang RS. Chen QS, et al. Analysis of dynamic blood pressure and heart rate in patients with anterior ischemic optic neuropathy. Chinese J fundus ophthalmopathy 2002;18:259 261.

12. Liu JHK, Bouligny RP, Kripe DF, et al. Nocturnal elevation of intraocular pressure is detectable in the sitting position. Invest Ophthalmol Vis Sci. 2003;44:4439-42.

13. Liu JHK, Kripe DF,Weinreb RN. Comparison of the nocturnal effects of once-daily timolol and latanoprost on intraocular pressure. Am J Ophthalmol. 2004;138:389-95.

14. Lee JY, Yoo C, Kim YY. The effect of lateral Decubitus position on intraocular pressure in patients with untreated open-angle glaucoma. Am J Ophthalmol. 2013;155:329-35. 
15. Kim KN, Jeoung JW, Park KH, et al. Effect of lateral Decubitus position on intraocular pressure in glaucoma patients with asymmetric visual field loss. Ophthalmology. 2013;120:731-5.

16. Lee TE, Yoo C, Kim YY. Effects of different sleeping postures on intraocular pressure and ocular perfusion pressure in healthy young subjects. Ophthalmology. 2013;120:1565-70.

17. Yang, et al. Postural effects on intraocular pressure and ocular perfusion pressure in patients with non-arteritic anterior ischemic optic neuropathy. BMC Ophthalmology. 2017;17:47.

18. Hayreh SS. Ischemic optic neuropathy. Prog Retin Eye Res. 2009;28:34-62.

19. Tiffany Lacharme A, Almanjoumi F, Aptel, et al. Twenty-four-hour rhythm of ocular perfusion pressure in non-arteritic anterior ischaemic optic neuropathy. Acta Ophthalmol. 2014;92:e346-52.

20. Fabio N, Kanadani TCA, Moreira BSP, Bezerra, et al. Diurnal Curve of the Ocular Perfusion Pressure. Journal of Current Glaucoma Practice January-April. 2016;10(1):6.

21. Wang $M$, Wang RS, Wang $S$, et al. Clinical observation of ocular pressure intervention on ocular hemodynamic changes in ischemic ophthalmopathy. Chin j fundus ophthalmopathy. 2013;29(6):575-9.

22. Xue SC, Li HR. Effect of lowering intraocular pressure on ocular hemodynamics in nonarteriolitic anterior ischemic optic neuropathy. Chin j fundus ophthalmopathy. 2013;29(3):255-6.

\section{Figures}

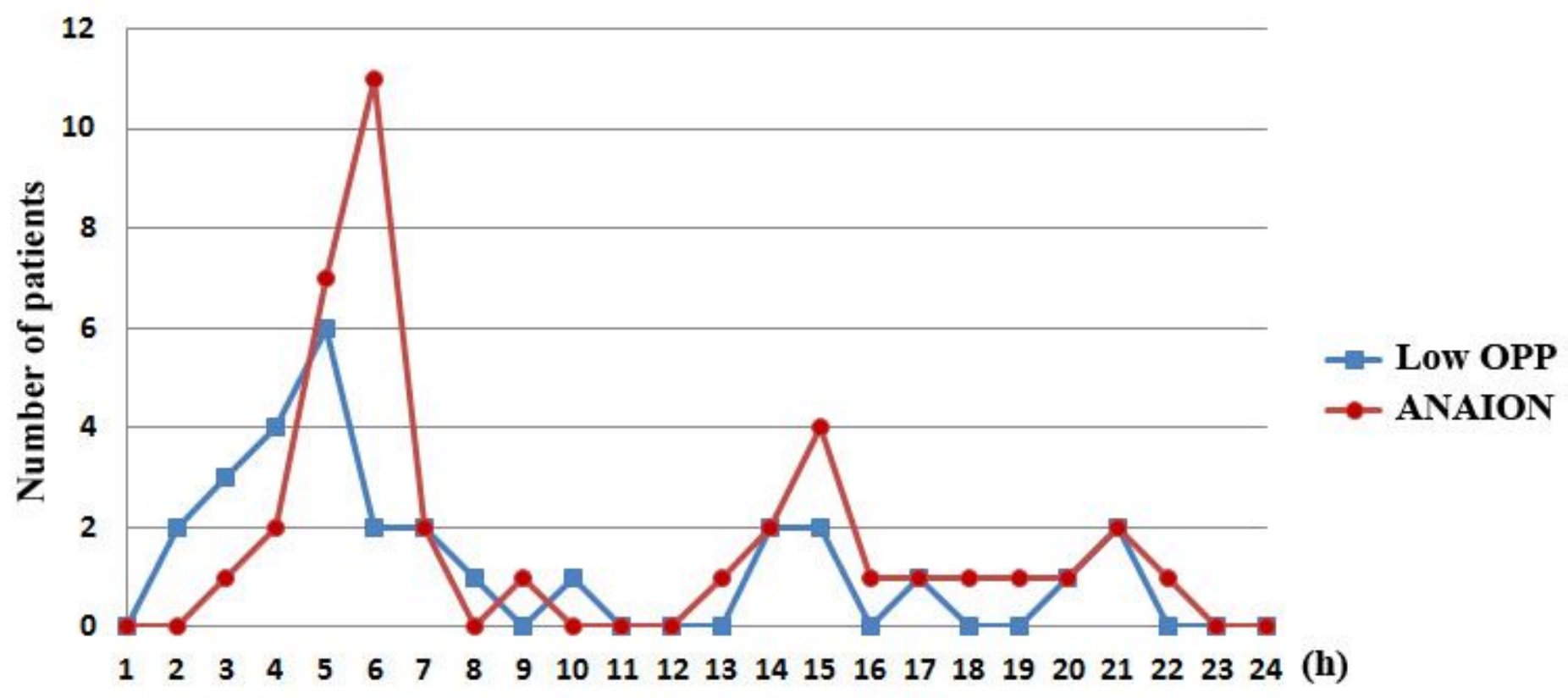

Figure 1

Onset of ANAION and low OPP in 37 patients 